AperTO - Archivio Istituzionale Open Access dell'Università di Torino

\title{
A Novel Raman Setup Based on Magnetic-Driven Rotation of Sample
}

\section{This is a pre print version of the following article:}

Original Citation:

\section{Availability:}

This version is available http://hdl.handle.net/2318/1678138

since 2020-02-28T14:31:54Z

Published version:

DOI:10.1007/s11244-018-1033-z

Terms of use:

Open Access

Anyone can freely access the full text of works made available as "Open Access". Works made available under a Creative Commons license can be used according to the terms and conditions of said license. Use of all other works requires consent of the right holder (author or publisher) if not exempted from copyright protection by the applicable law. 


\section{A novel Raman setup based on magnetic-driven rotation of sample}

Matteo Signorile*, Francesca Bonino, Alessandro Damin, and Silvia Bordiga

Department of Chemistry, NIS and INSTM Reference Centre, Università di Torino, Via G. Quarello 15, I-10135 and Via P. Giuria 7, I-10125, Torino, Italy

* Matteo Signorile, Tel: +39-011-6708383, Fax: +39-011-6707855, E-mail: matteo.signorile@unito.it

\section{Keywords}

Raman spectroscopy; in situ; magnetic sample holder; sample damaging; catalyst

Abstract

The Raman characterization of catalysts (as for any material) is generally a difficult task, since the numerous drawbacks affecting this technique, e.g. overlapping with photoemission phenomena and excitation induced sample damaging. These side effects are detrimental toward advanced applications of Raman spectroscopy, as in situ and/or operando ones. If photoemission can be often avoided by changing the excitation wavelength, the sample damaging requires to take advantage of specific tools, developed ad hoc. The aim of this work is to show the potentialities of a novel Raman setup, specifically designed for the in situ study of catalytic materials, where the sample is moved by means of a magnetic-driven sample-holder), reducing the excitation induced damaging to a negligible extent. Various examples related to catalysis field (involving inorganic, organic and mixed systems) are reported to support this statement. 


\section{Introduction}

Raman spectroscopy is a useful characterization tool in the field of catalysis, which has provided a significant contribution in the past toward the study of several materials (see e.g. [1-28]). However, the Raman approach to catalyst characterization is often a demanding task, because of the drawbacks affecting it. Among the main reasons, the overlap of photoluminescence phenomena and the sample damaging induced by the intense excitation lasers are the most critical ones. The former can be solved by choosing an excitation wavelength sufficiently far from the typical emission region (i.e. UV or IR) [17] or by adopting advanced setups filtering the fluorescence taking advantage of its time delay with respect to Raman [29, 30]. The latter, instead, can be addressed through different strategies. In most of the cases, the reduction of the excitation source power is sufficient to avoid decomposition. However, such approach is not optimal in every situation, since it leads to the increase of the measurement time and, consequently, to the loss of time resolution. Thereby, applying Raman spectroscopy to the study dynamic phenomena (e.g. chemical reactions, even if slow) turns to be impossible under this limitation. Furthermore, power reduction is sometime insufficient in avoiding sample degradation: this is the case of materials which are highly absorbing the excitation wavelength, or when high energy excitation lines (e.g. UV ones) are exploited. These intrinsic limitations of Raman spectroscopy make difficult to follow the evolution in the experimental complexity naturally followed by other techniques, i.e. toward in situ and/or operando conditions. Indeed, few pioneering examples are encountered in the literature [15, 13, 24, 12, 16, 14, 27, 28].

To be able to exploit the full excitation power without damaging the sample is then of outmost importance. A smart strategy is to exploit the sample movement: several examples are reported in the literature, offering various technological solutions $[15,13,12,16,31]$. The first example of a Raman measurement performed with a moving sample reported in the literature is probably represented by the rotating sample holder developed by Kiefer and Bernstein in 1971 [31]. The concept of the device is simple: the powder was pressed in a circular groove of the sample holder (forming a ring-shaped, self-supported pellet) and the analysis was performed sampling the material while it is rotated. This solution allowed its inventors to measure a highly absorbing material such as potassium permanganate without destroying it, thus demonstrating the positive effect of the sample rotation. 
The same concept was exploited again some years later by Cheng and coworkers [16]. The proposed device introduced several evolutions with respect to the previous one: the rotating sample holder was enveloped by a sealed chamber, allowing to expose the sample to the desired pressure/flow of a gas or to vacuum. Furthermore, temperature control was possible through an external furnace and/or by flowing gases at a given temperature. The rotation was transmitted to the sample holder from an external motor and the coupling of the two parts was probably the most complex feature of the cell (and its Achilles' heel too). Because of the complicated driving system, the cell «presents technical problems in minimizing the mechanical distortions [...] and in the sealing of the cell» as later commented by Müller and Weber [15].

The latter proposed a new solution, where the novelty was to avoid any mechanical part in the controlled atmosphere region of the cell, ascribing to the complex system of transmission of motion the weakness of the previous setup. Thus, instead of moving the sample itself, it was scanned by a movable laser beam: the incoming light was reflected by a rotating prismatic mirror, changing time by time the position of the measurement spot on the material. The scattered light was then recollected by a concave mirror and directed to the collection optics. Even if such solution simplified the problem of the cell sealing, it introduced new sources of aberration: it is possible to infer that the optimal collection of the Raman signal required a highquality alignment of the optical elements, so each experiment was necessarily preceded by a time consuming optimization of the Raman instrumentation.

Reaching the 2000's, the development of new Raman setups was progressively oriented to the study of reactions while occurring, i.e. carrying out the measurements in the so called operando conditions [14]. Anticipating the definition by Bañares, Chua and Stair developed a new type of cell, more precisely definable as a reactor [13]. Even if the processes were not followed by online products analysis, the reactor was constructed in order to allow the spectroscopic study in realistic reaction conditions: in particular the authors focused on the formation of coke upon conversion of Methanol to Hydrocarbons (MTH) on zeolites, thus the use of a UV-Raman setup was compulsory to avoid the strong emission of the coke species [24]. Since the risk of laserinduced damage is highly probable in these conditions [32], the sample was moved during the measurement by exploiting a smart trick, the catalytic bed fluidization: the continuous exchange of the catalyst particles under the beam avoids their decomposition due to the laser. The fluidization is achieved in this device combining the effect of a gas flowing through the catalytic 
bed and the electromagnetic shaking of the whole reactor. The setup was really effective, since strong UV absorber like Polycyclic Aromatic Hydrocarbons (PAHs) were effectively measured avoiding any type of damage [24].

The most recent example of Raman setup with movable sample is due to Beato and coworkers, realized by modifying a commercial Linkam CCR1000 reactor-cell [12]. This cell exploits the catalytic bed fluidization too, but it is based on a fully fluid-dynamic concept: the powder is fluidized by backflow pulses with regular frequency, produced via dedicated device. The versatility of this tool has been demonstrated by application involving several heterogeneous catalysts $[12,27,28]$. Despite its excellent capability to preserve the sample from laserdegradation, fluidization is also a possible source of drawbacks: i) unavoidably the sample is partially lost during the experiment, limiting the time framework available to perform it; ii) the continuous friction among the particles leads to their progressive morphological modification, so that occasionally the fluidization conditions (strongly connected to the particles shape and size) are no longer achievable iii) in presence of condensable vapors, the wetting of the catalyst can prevent the fluidization to occur; and iv) since a gas flow is required to fluidize the powder, the reactor-cell is not suitable for working in batch (i.e. static conditions) or in vacuum.

Keeping advantage of these works and combining it with the long experience in setups development of our group [33-37], we designed and tested a novel tool for Raman spectroscopy. Exploiting sample rotation to preserve it from degradation at full excitation power, it takes advantage of an innovative way of motion transmission, based on the application of an external magnetic field.

\section{Experimental}

\subsection{Description of the setup}

The core of the setup is represented by its innovative sample holder. The mechanical force requested to generate a rotary motion of the sample is transmitted as in a common magnetic stirrer, i.e. applying an external rotating magnetic field. The sample holder contains a permanent magnet, which is forced to align to the applied field, thus producing the sample movement. The advantage of this configuration, with respect to previous examples [16,31], is the positioning of all the mechanical parts far from the sample holder, as the motion is transmitted in a contactless 
way. Thereby, the sample holder can be hosted in closed containers (e.g. a spectroscopy cell), however being still movable. A schematic of sample holder is given in Figure 1.

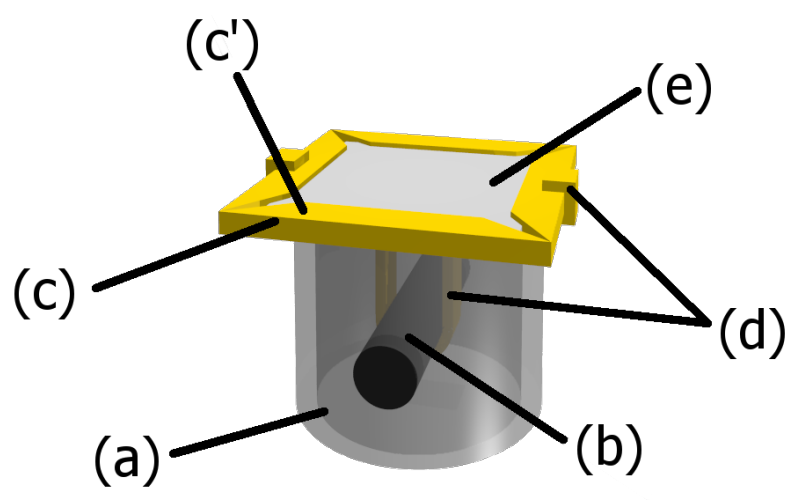

Figure 1. Schematic of the sample holder and its main components: (a) hollow stainless steel cylinder; (b) magnetic element; (c) gold envelop equipped with foldable winglets (c'); (d) mounting gold strip; and (e) sample in pellet form.

A hollow stainless steel cylinder constitutes the body of the sample holder. The magnetic element is an AlNiCo-5 bar, mounted across the cylinder: the choice of this magnetic alloy is due to its high Curie temperature (above $800{ }^{\circ} \mathrm{C}$, allowing to perform high temperature activation treatment without losing the magnetization) and to its reasonable magnetic coercivity (about 50 $\mathrm{kA} \mathrm{m}^{-1}$ ). By comparison, a neodymium based magnet can reach 15-20 times higher coercivity values, but it will never be suitable for high temperature applications because of the lower Curie temperature $\left(300{ }^{\circ} \mathrm{C}\right)[38]$. On the upper part of the cylinder, a square gold envelope is mounted: the envelope is fixed to the cylinder through a gold strip and it hosts the sample in form of selfsupported pellet. Four foldable winglets, integrated within the gold envelope, keep the pelleted sample in the right position. Being the sample integrated in the sample holder, the former rotates together with the latter as the external field is applied.

The design of the sample holder allows a certain degree of miniaturization, such as it can be built with a diameter lower than $1 \mathrm{~cm}$. This fact is really practical for in situ applications, since the small sample holder can easily fit a Raman spectroscopy cell. An example of the standard design of the latter is given in Figure 2. 


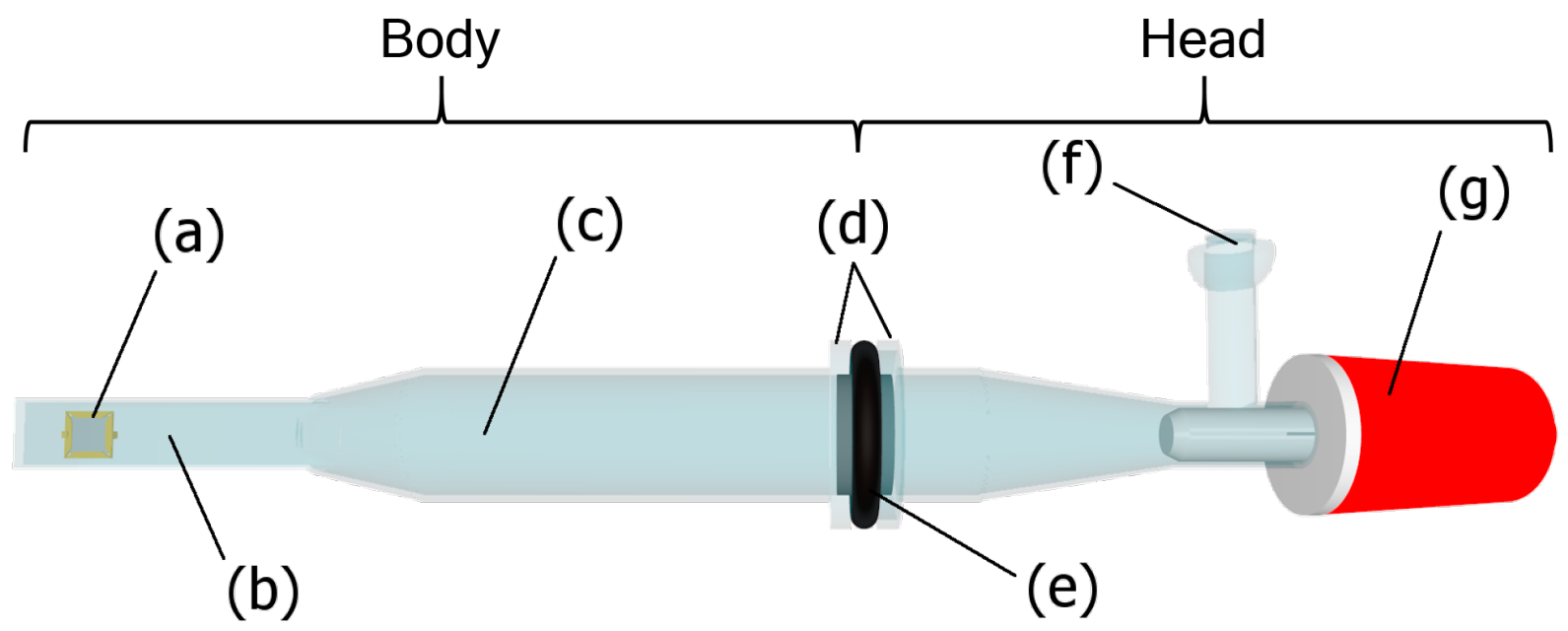

Figure 2. Sketch of a typical Raman spectroscopy cell and its main parts: (a) sample holder (see Figure 1); (b) optical grade quartz glass cuvette; (c) quartz glass tube; (d) glass KF-type flanges; (e) Viton O-ring; (f) Rotulex-type connection to gas/vacuum manifold; and (g) PTFE tap.

The cell has a simple design and it can be divided in two blocks: the "body" (containing the optical part) and the "head" (allowing the connection of the cell to a gas manifold). Starting from the former, the optical part is constituted by a standard $10 \mathrm{~mm}$ cuvette of Suprasil quartz-glass, guaranteeing a good transparency and the absence of emission phenomena also in the UV spectral region. The cuvette is welded to a quartz glass tube, able to resist the high temperature the sample should reach during activation. The body is connected to the head through a KFflanges system, sealed by a Viton O-ring and mechanically kept in place by a clamp. By removing the clamp, the cell can be divided in the two parts allowing the introduction of the sample, as well as an accurate cleaning of the device. The head includes a PTFE tap, which allows the connection of the cell to a gas manifold through a Rotulex type, grease-free connection.

This type of setup has been successfully applied in some recent works where fast and reliable Raman and UV-Raman measurements were required [32, 20, 9]. Because of its effectiveness and competitive construction costs, a patent request has been submitted [39]. Future upgrades will introduce temperature control and the possibility to exploit gas flows, progressively opening to the application of the setup under in situ and operando conditions. 


\subsection{Benchmark experiments}

The reliability of the Raman measurements obtained through the presented setup has been checked over a set of representative materials/conditions relevant in the catalysis field. Inorganic, organic and mixed systems have been considered. In detail, the reported test cases involve bulk molybdenum disulfide ( $\mathrm{MoS}_{2}$, Fluka), bulk anthracene (Aldrich, 99\%) and methanol (Aldrich, 99.9\%, anhydrous) adsorbed over a protonic ZSM-5 zeolite (Süd Chemie, $\mathrm{Si} / \mathrm{Al}=45$ ) from gas phase at room temperature (RT).

The measurements have been performed exploiting three Renishaw inVia Raman Microscope spectrometers, equipped with different laser lines ranging from NIR to mid-UV. In the present work, three of these have been exploited: $514.5 \mathrm{~nm}$ ( $\mathrm{Ar}^{+}$laser, Spectra Physics 163-C4210), 442 $\mathrm{nm}$ (He-Cd laser, Kimmon IK5651R-G) and $244 \mathrm{~nm}$ (frequency doubled $\mathrm{Ar}^{+}$, Coherent 300C MotoFreD). Measurements have been carried out with the full laser power at the sample, i.e. among 10-20 $\mathrm{mW}$ for visible lasers and about $5 \mathrm{~mW}$ for the mid-UV one.

$\mathrm{MoS}_{2}$ and naphthalene have been measured as such in air, whereas the methanol adsorption over ZSM-5 was preceded by the thermal activation of the latter. In detail, the sample was heated under vacuum (residual pressure $<10^{-3} \mathrm{mbar}$ ) up to $550{ }^{\circ} \mathrm{C}$ with a slope of $5{ }^{\circ} \mathrm{C} / \mathrm{min}$, then exposed to a pressure of 100 mbar of $\mathrm{O}_{2}$ for $1 \mathrm{~h}$. Oxygen has been then outgassed and the sample was cooled back to RT. Later, methanol has been dosed exposing the activated ZSM-5 to its vapor pressure $(\sim 130$ mbar at $\mathrm{RT})$.

\section{Results and Discussion}

Inorganic materials (including many heterogeneous catalysts) are routinely characterized through Raman spectroscopy, without special efforts regarding their stability in measurement conditions since they are considered as stable phases. If generally this is true, some peculiar materials (usually highly absorbing ones) should be handled with care. This was the case of materials such as potassium permanganate or molybdenum disulfide $\left(\mathrm{MoS}_{2}\right)$, whose characterization drove to the construction of some of the setups previously discussed [15, 31].

$\mathrm{MoS}_{2}$ is of particular interest, because of its various application fields. Traditionally, it has been exploited (in a supported form) in hydrodesulfurization catalysis [40]. More recently its peculiar electronic and optical properties upon exfoliation (i.e. reducing its dimensionality toward a 2D 
material) have been discovered $[41,42]$, opening to new applications in the development of electronic devices [43-45].

Raman spectroscopy is one of the election tools in $\mathrm{MoS}_{2}$ characterization, since a clear correlation among the frequency of its main vibrational signals (a doublet of bands, ascribable to modes of $\mathrm{A}_{1 \mathrm{~g}}$ and $\mathrm{E}_{2 \mathrm{~g}}^{1}$ symmetry) and the number of layer constituting the particle has been demonstrated [46-48]. Interestingly, the same are similarly affected by temperature increases: such behavior has been observed both in case of controlled heating of the sample [49] and overexposure to the excitation laser beam [50]. This latter feature makes $\mathrm{MoS}_{2}$ an optimal test case to verify the reliability of the developed setup. The test measurements were performed with $514.5 \mathrm{~nm}$ and $442 \mathrm{~nm}$ excitations, both on the sample in rotation or static. The obtained Raman spectra are reported in Figure 3.
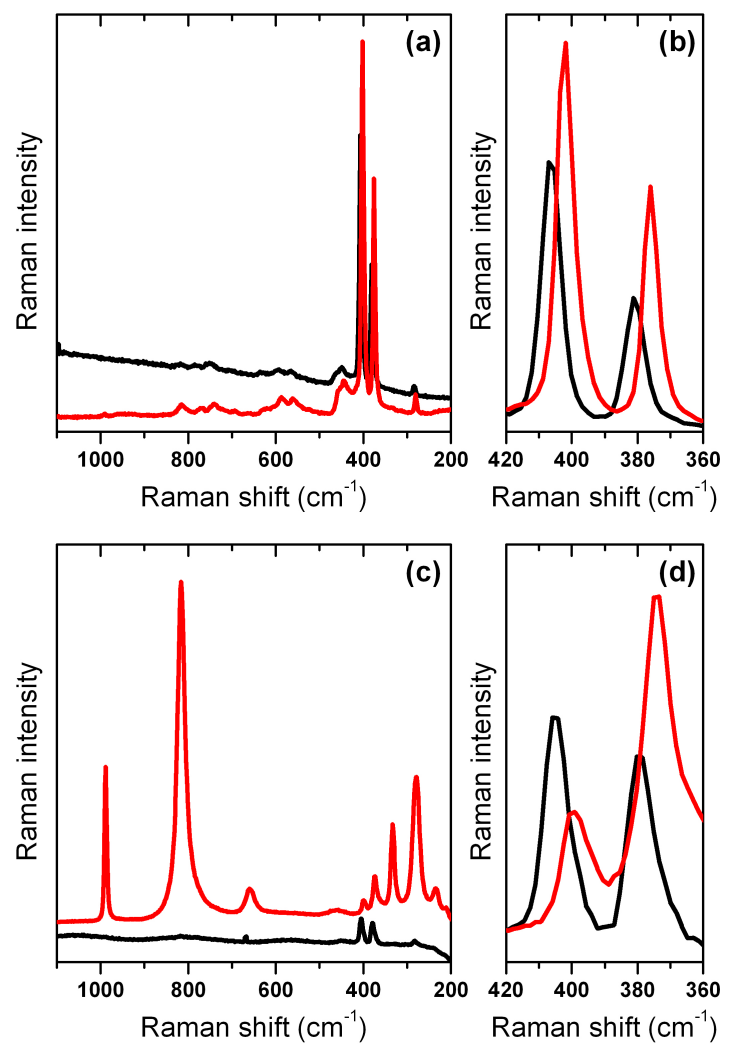

Figure 3. Raman spectra of bulk $\mathrm{MoS}_{2}$ collected while rotating (black lines) or with static sample (red lines). Spectra were collected exploiting $514.5 \mathrm{~nm}$ (a-b) and $442 \mathrm{~nm}$ (c-d) excitation sources, at full laser power and exposing the sample for $10 \mathrm{~s}$ to the beam. Panels (b) and (d) 
show the detail of the characteristic $A_{1 g}-E_{2 g}^{1}$ doublet of $\mathrm{MoS}_{2}$. Spectra have been vertically shifted for sake of visualization.

Considering the $514.5 \mathrm{~nm}$ excitation first, both rotating and static measurements show similar features on the considered spectral range. Looking with higher detail to the $A_{1 g}-E_{2 g}^{1}$ doublet, the measurement performed with rotating sample allows to determine their maxima at $407 \mathrm{~cm}^{-1}$ and $381 \mathrm{~cm}^{-1}$ as expected from previous literature [46, 47]. Conversely, a clear redshift of $5 \mathrm{~cm}^{-1}$ of both modes is observed upon static measurement, most probably ascribable to laser induced heating. According to the model of Najmaei et al. [49], the frequency-temperature dependence can be quantified in about $-0.014 \mathrm{~cm}^{-1} / \mathrm{K}$ for highly layered $\mathrm{MoS}_{2}$. Thereby, the temperature of the sample at the measurement spot reaches $\sim 80^{\circ} \mathrm{C}$.

Even more representative is the outcome with the $442 \mathrm{~nm}$ laser, where the static measurement leads to the degradation of the sample: as observed in Figure 3c, the spectral features look completely different from ones collected in rotation, testifying the excitation beam promoted some reactivity. The obtained spectrum is straightforwardly assigned to molybdenum (VI) oxide $\left(\mathrm{MoO}_{3}\right)$, as suggested by the intense bands at $995 \mathrm{~cm}^{-1}$ and $820 \mathrm{~cm}^{-1}$ (ascribed to $v(\mathrm{Mo}=\mathrm{O})$ and $v_{\text {asym }}\left(\right.$ Mo-O-Mo) modes respectively) and typical group of bands among 200-400 $\mathrm{cm}^{-1}$ (due to $\delta(\mathrm{Mo}=\mathrm{O})$ vibrations) [51]. The energy delivered by the $442 \mathrm{~nm}$ laser in $10 \mathrm{~s}$ of exposure is then sufficient to promote the complete oxidation of $\mathrm{MoS}_{2}$ with the only atmospheric oxygen partial pressure. Exploiting rotation, instead, the sulfide phase is preserved without showing signs of incipient oxidation.

If inorganic materials rarely show degradation to the extent of $\mathrm{MoS}_{2}$, the behavior of organic species is often more problematic under this point of view. The ease of organic sample degradation was another relevant driving force toward the development of dedicated Raman setups, since their importance in the catalysis field $[13,12]$. The second test case reported in this work deals with a demanding system: anthracene. Anthracene belongs to the group of Polycyclic Aromatic Hydrocarbons (PAHs), a class of ubiquitous molecules investigated in the fields of environmental sciences, toxicology, earth sciences, astrochemistry and catalysis [52-58]. Concerning the latter topic, PAHs have been identified as deactivating species in several refining and petrochemical processes, e.g. Methanol To Hydrocarbons (MTH) [57-59]. Because of their 
thermodynamical stability and their large dynamic volume, PAHs brings MTH catalysts (acid zeolites and zeotypes) to deactivation by sticking in the porous system without the possibility to further react and/or out-diffuse [57, 58]. Raman spectroscopy is a demanding technique toward PAHs characterization, since these are highly fluorescent molecules. Indeed, the only possibility to effectively collect their Raman spectra is to move the excitation wavelength far from the emission range (i.e. the visible), thus avoiding the interference of fluorescence in the detection of the Raman signal [17]. In the present work, mid-UV excitation (244 nm) has been applied to the characterization of anthracene (as prototype of PAH): the results are reported in Figure 4.

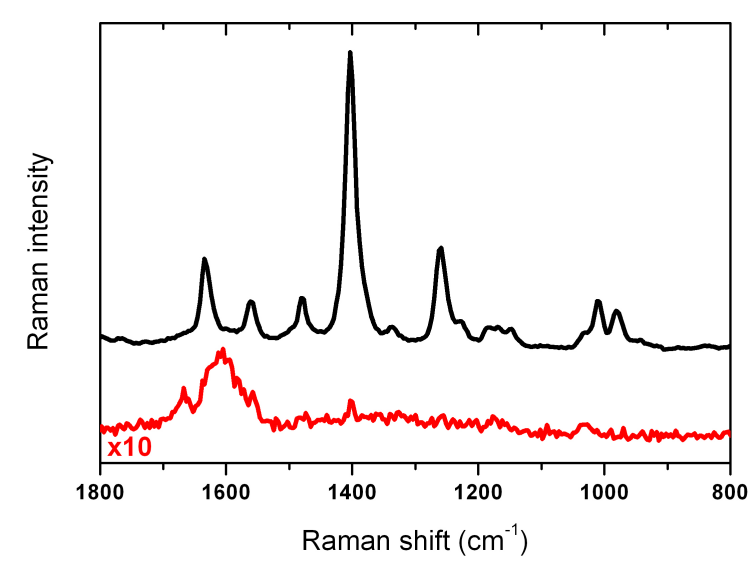

Figure 4. UV-Raman $(\lambda=244 \mathrm{~nm})$ spectra of anthracene collected while rotating (black lines) or with static sample (red lines). Spectra have been collected at full laser power, with an exposure time of 120 s. Spectra have been vertically shifted for sake of visualization. The spectrum collected in static conditions has been multiplied by a factor 10 for the same reason.

The importance of exploiting sample movement in UV-Raman measurements of organic species is clearly depicted in Figure 4. The high energy carried by UV photons is extremely harmful, since it brings to fast decomposition of molecules if measurements are carried out without precautions. Anthracene is a clear example of such undesired effect: thanks to resonance enhancement (allowed by its electronic transitions, falling in the mid-UV region [60]), a high quality spectrum can be collected in only $120 \mathrm{~s}$ if rotation is exploited. Conversely it is impossible to perform the same measurement with static sample, since it readily decomposes toward bulkier carbonaceous, as testified by the growth of the well known $\mathrm{G}$ band $[61,62]$. The D band is instead hardly detectable, as expected with UV excitation [62]. A further peak appears 
at $\sim 1670 \mathrm{~cm}^{-1}$, compatibly with oxidation processes leading to the formation of carbonyl moieties. The most intense signal of anthracene $\left(\sim 1400 \mathrm{~cm}^{-1}\right)$ instead almost disappears, being now 80 times less intense than in the spectrum collected under sample rotation.

In the last example, a complex experiment is presented. In detail, methanol was dosed from gas phase on a protonic zeolite $(\mathrm{ZSM}-5, \mathrm{Si} / \mathrm{Al}=45)$. This test can be regarded as the zero-step of a MTH in situ study, since it could demonstrate the reactant stability in the measurement conditions, i.e. guaranteeing the results will be due to the true catalyst reactivity and not to spurious, laser induced effects. As in the previous examples, the results collected while rotating the sample are compared with the "static" ones in Figure 5.
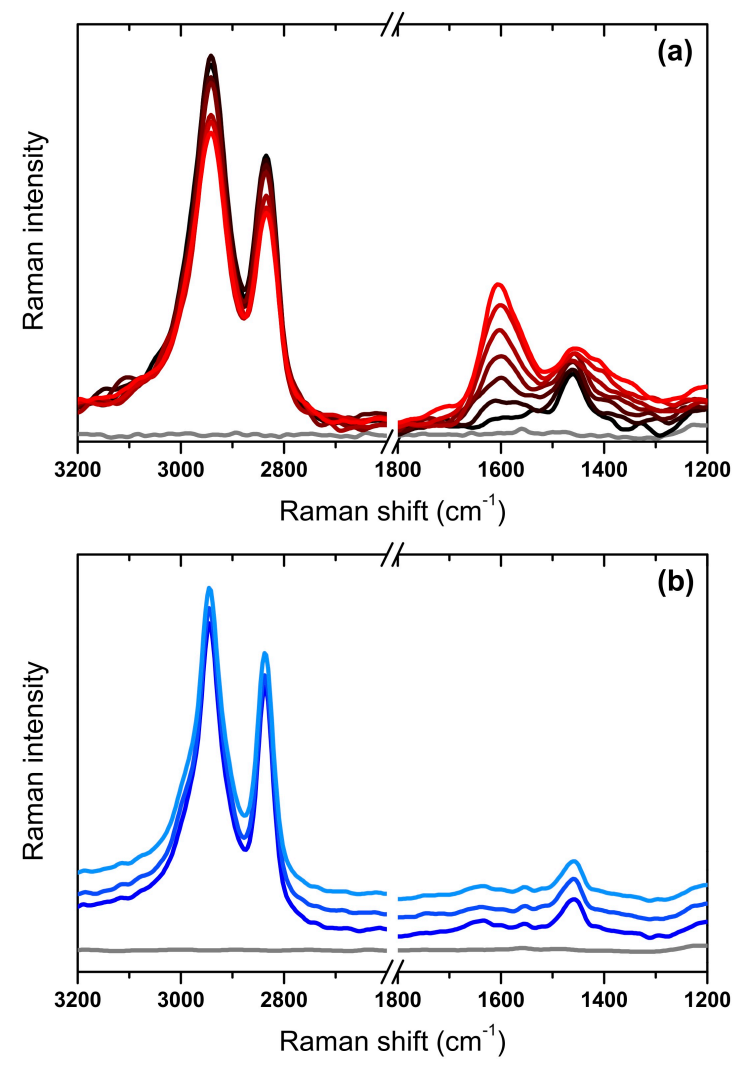

Figure 5. Raman spectra of bulk methanol adsorbed from gas phase on H-ZSM-5 collected with static (a) or rotating (b) sample. The time evolution is from black to red in panel (a) and from dark to light blue in panel (b). The spectrum of the activated H-ZSM-5 (grey line) is reported for comparison. The spectra where collected exploiting full laser power. The exposure time was set to $30 \mathrm{~s}$ for static sample spectra (panel a), whereas it has been increased to $300 \mathrm{~s}$ for ones 
collected while rotating (panel b). Furthermore, the latter have been vertically shifted for sake of visualization.

The last example depicts the importance of performing reliable Raman measurements in the catalysis field. In fact, when rotation was not applied, a clear spectral evolution is observed at increasing times. The high frequency signal ascribable to adsorbed methanol (peaks at $2840 \mathrm{~cm}^{-1}$ and $2945 \mathrm{~cm}^{-1}$, ascribable to $\mathrm{C}-\mathrm{H}$ stretching modes [63]) are progressively eroded, testifying that the amount of adsorbed methanol has been reducing. Further piece of information arises from the low frequency region, where on top of the methanol modes $\left(\mathrm{CH}_{3}\right.$ deformation modes at $\sim 1460$ $\left.\mathrm{cm}^{-1}[63]\right)$ new spectral features evolve with the time. The latter can be generically ascribed to the formation of coke-like species, as observed upon deactivation of MTH catalysts [24, 12, 9]. Such evidence must be carefully taken in account, since the excitation light is able to promote a reactivity similar to the one expected in the true process conditions. Thereby, the exploitation of a dedicated setup is compulsory, since the overlap of real and spurious process will lead to a misleading interpretation of the spectroscopic outcomes. While rotation is applied, instead, methanol is fully stable at the H-ZSM-5 surface for a long time. Each of the spectra reported in Figure $5 \mathrm{~b}$ refers to an exposure time equal to the one experienced by the sample along the whole set of spectra reported in Figure 5a. Even after three repetitions (i.e. exposing the sample to the laser for $15 \mathrm{~min}$ ), the methanol spectrum doesn't show any alteration. This demonstrates the present setup can be successfully exploited in MTH studies without affecting the results because of the spurious degradation on methanol induced by the excitation source.

\section{Conclusions}

This work presents a novel approach to Raman spectroscopy, allowing to perform in situ (and in future, operando) experiments, based on a dedicated experimental setup. The core of the latter is represented by its innovative sample holder, which allows the sample movement through the application of an external magnetic field. Avoiding the presence of mechanical parts inside the controlled atmosphere region of the Raman cell, the sealing of the latter is guaranteed, overcoming a serious side effect of past implementation. The effectiveness of the device is demonstrated by several examples simulating conditions often encountered in catalytic systems. The opportunity to exploit the full excitation power (still avoiding sample degradation) pushes 
the time resolution of Raman spectroscopy down to its limits, opening to the study of dynamic phenomena (e.g. reactions).

\section{Acknowledgments}

This work is part of the $\mathrm{PhD}$ thesis of MS. The authors acknowledge Raffaele Disa (Disa Raffaele e F.lli s.a.s., Milano, Italy) for the discussion on design and development of the Raman setup and the realization of the cell prototypes.

\section{References}

1. Stavitski E, Weckhuysen BM (2010) Infrared and Raman imaging of heterogeneous catalysts. Chem Soc Rev 39:4615. doi: 10.1039/c0cs00064g

2. Wachs IE (1996) Raman and IR studies of surface metal oxide species on oxide supports: Supported metal oxide catalysts. Catal Today 27:437-455. doi: 10.1016/09205861(95)00203-0

3. Wachs IE, Roberts CA (2010) Monitoring surface metal oxide catalytic active sites with Raman spectroscopy. Chem Soc Rev 39:5002. doi: 10.1039/c0cs00145g

4. Bañares MA, Wachs IE (2002) Molecular structures of supported metal oxide catalysts under different environments. J Raman Spectrosc 33:359-380. doi: 10.1002/jrs.866

5. Bordiga S, Damin A, Bonino F, et al (2003) Resonance Raman effects in TS-1: the structure of $\mathrm{Ti}(\mathrm{iv})$ species and reactivity towards $\mathrm{H} 2 \mathrm{O}, \mathrm{NH} 3$ and $\mathrm{H} 2 \mathrm{O} 2$ : an in situ studyPresented at the International Congress on Operando Spectroscopy, Lunteren, The Netherlands, March 2-6, 2003. Phys Chem Chem Phys 5:4390-4393. doi: $10.1039 / \mathrm{b} 306041 \mathrm{c}$

6. Guo Q, Feng Z, Li G, et al (2013) Finding the "Missing Components" during the Synthesis of TS-1 Zeolite by UV Resonance Raman Spectroscopy. J Phys Chem C 117:2844-2848. doi: 10.1021/jp310900a

7. Wang L, Xiong G, Su J, et al (2012) In situ UV Raman spectroscopic study on the reaction intermediates for propylene epoxidation on TS-1. J Phys Chem C 116:9122- 
9131. doi: $10.1021 / \mathrm{jp} 3017425$

8. Bonino F, Damin A, Piovano A, et al (2011) Direct Evidence of Highly Dispersed Iron in Fe-silicalite: A Raman Spectroscopic Study. ChemCatChem 3:139-142. doi: $10.1002 /$ cctc. 201000265

9. Rojo-Gama D, Signorile M, Bonino F, et al (2017) Structure-deactivation relationships in zeolites during the methanol-to-hydrocarbons reaction: Complementary assessments of the coke content. J Catal 351:33-48. doi: 10.1016/j.jcat.2017.04.015

10. Hu H, Wachs IE (1995) Surface Structures of Supported Molybdenum Oxide Catalysts: Characterization by Raman and Mo L3-Edge XANES. J Phys Chem US 99:10897-10910.

11. Mestl G, Srinivasan TKK (1998) Raman Spectroscopy of Monolayer-Type Catalysts: Supported Molybdenum Oxides. Catal Rev 40:451-570. doi: $10.1080 / 01614949808007114$

12. Beato P, Schachtl E, Barbera K, et al (2013) Operando Raman spectroscopy applying novel fluidized bed micro-reactor technology. Catal Today 205:128-133. doi: 10.1016/j.cattod.2012.09.030

13. Chua Y, Stair PC (2000) A Novel Fluidized Bed Technique for Measuring UV Raman Spectra of Catalysts and Adsorbates. J Catal 196:66-72. doi: 10.1006/jcat.2000.3017

14. Bañares MA (2005) Operando methodology: combination of in situ spectroscopy and simultaneous activity measurements under catalytic reaction conditions. Catal Today 100:71-77. doi: 10.1016/j.cattod.2004.12.017

15. Müller A, Weber T (1991) In situ raman investigation of hydrodesulphurization catalysts. Appl Catal 77:243-250. doi: 10.1016/0166-9834(91)80069-9

16. Cheng CP, Ludowise JD, Schrader GL (1980) Controlled-Atmosphere Rotating Cell for in Situ Studies of Catalysts Using Laser Raman Spectroscopy. Appl Spectrosc 34:146-150. doi: $10.1366 / 0003702804730727$

17. Fan F, Feng Z, Li C (2010) UV Raman spectroscopic studies on active sites and synthesis 
mechanisms of transition metal-containing microporous and mesoporous materials. Acc Chem Res 43:378-387. doi: 10.1021/ar900210g

18. Bordiga S, Lamberti C, Bonino F, et al (2015) Probing zeolites by vibrational spectroscopies. Chem Soc Rev 44:7262-7341. doi: 10.1039/c5cs00396b

19. Knops-Gerrits P-P, De Vos DE, Feijen EJP, Jacobs PA (1997) Raman spectroscopy on zeolites. Microporous Mater 8:3-17. doi: http://dx.doi.org/10.1016/S09276513(96)00088-0

20. Signorile M, Bonino F, Damin A, Bordiga S (2016) UV-Raman Fingerprint of Brønsted Sites in MFI Zeolites: A Useful Marker in Dealumination Detection. J Phys Chem C 120:18088-18092. doi: 10.1021/acs.jpcc.6b05520

21. Ricchiardi G, Damin A, Bordiga S, et al (2001) Vibrational structure of titanium silicate catalysts. A spectroscopic and theoretical study. J Am Chem Soc 123:11409-11419. doi: $10.1021 / \mathrm{ja} 010607 \mathrm{v}$

22. Su J, Xiong G, Zhou J, et al (2012) Amorphous Ti species in titanium silicalite-1: Structural features, chemical properties, and inactivation with sulfosalt. J Catal 288:1-7. doi: $10.1016 /$ j.jcat.2011.12.006

23. Bordiga S, Damin A, Bonino F, et al (2002) The structure of the peroxo species in the TS1 catalyst as investigated by resonant Raman spectroscopy. Angew Chemie-International Ed 41:4734-4737. doi: 10.1002/anie.200290032

24. Chua YT, Stair PC (2003) An ultraviolet Raman spectroscopic study of coke formation in methanol to hydrocarbons conversion over zeolite H-MFI. J Catal 213:39-46. doi: 10.1016/s0021-9517(02)00026-X

25. Wragg DS, Grønvold A, Voronov A, et al (2013) Combined XRD and Raman studies of coke types found in SAPO-34 after methanol and propene conversion. Microporous Mesoporous Mater 173:166-174. doi: 10.1016/j.micromeso.2013.02.022

26. Li C, Stair PC (1997) Ultraviolet Raman spectroscopy characterization of coke formation in zeolites. Catal Today 33:353-360. doi: 10.1016/s0920-5861(96)00120-4 
27. Signorile M, Damin A, Budnyk A, et al (2015) MoS2 supported on P25 titania: A model system for the activation of a HDS catalyst. J Catal 328:225-235. doi: 10.1016/j.jcat.2015.01.012

28. Cavalca F, Beato P, Hyldtoft J, et al (2017) Vanadia-Based Catalysts for the Sulfur Dioxide Oxidation Studied In Situ by Transmission Electron Microscopy and Raman Spectroscopy. J Phys Chem C 121:3350-3364. doi: 10.1021/acs.jpcc.6b10711

29. Matousek P, Towrie M, Stanley A, Parker AW (1999) Efficient rejection of fluorescence from Raman spectra using picosecond Kerr gating. Appl Spectrosc 53:1485-1489. doi: $10.1366 / 0003702991945993$

30. Matousek P, Towrie M, Ma C, et al (2001) Fluorescence suppression in resonance Raman spectroscopy using a high-performance picosecond Kerr gate. J Raman Spectrosc 32:983988. doi: $10.1002 /$ jrs.784

31. Kiefer W, Bernstein HJ (1971) Rotating Raman Sample Technique for Colored Crystal Powders; Resonance Raman Effect in Solid KMnO4. Appl Spectrosc 25:609-613. doi: $10.1366 / 000370271779951101$

32. Signorile M, Bonino F, Damin A, Bordiga S (2015) In Situ Resonant UV-Raman Spectroscopy of Polycyclic Aromatic Hydrocarbons. J Phys Chem C 119:11694-11698. doi: 10.1021/acs.jpcc.5b02209

33. Borello E, Zecchina A, Morterra C (1967) Infrared study of methanol adsorption on Aerosil. I. Chemisorption at room temperature. J Phys Chem 71:2938-2945. doi: $10.1021 / \mathrm{j} 100868 \mathrm{a} 027$

34. Zecchina A, Stone FS (1974) Reflectance spectra of CO chemisorbed on $\mathrm{MgO}$, and evidence for the formation of cyclic adsorbed species. J Chem Soc Chem Commun 582. doi: 10.1039/c39740000582

35. Spoto G, Zecchina A, Bordiga S, et al (1994) Cu(I)-ZSM-5 zeolites prepared by reaction of $\mathrm{H}-\mathrm{ZSM}-5$ with gaseous $\mathrm{CuCl}$ : Spectroscopic characterization and reactivity towards carbon monoxide and nitric oxide. Appl Catal B, Environ 3:151-172. doi: 10.1016/0926- 
3373(93)E0032-7

36. Lamberti C, Prestipino C, Bordiga S, et al (2003) Description of a flexible cell for in situ $\mathrm{X}$-ray and far-IR characterization of the surface of powdered materials. Nucl Instruments Methods Phys Res Sect B Beam Interact with Mater Atoms 200:196-201. doi: 10.1016/S0168-583X(02)01719-6

37. Spoto G, Gribov EN, Ricchiardi G, et al (2004) Carbon monoxide $\mathrm{MgO}$ from dispersed solids to single crystals: A review and new advances. Prog Surf Sci 76:71-146. doi: 10.1016/j.progsurf.2004.05.014

38. Cullity BD, Graham CD (2008) Hard Magnetic Materials. In: Introd. to Magn. Mater. John Wiley \& Sons, Inc., Hoboken, NJ, USA, pp 477-504

39. Damin A, Signorile M, Bonino F, et al (2015) Cella per analisi mediante spettroscopia Raman.

40. Topsøe H, Clausen BS, Massoth FE (1996) Hydrotreating Catalysis and Science and Technology. Springer-Verlag, Berlin/Heidelberg

41. Shi H, Yan R, Bertolazzi S, et al (2013) Exciton Dynamics in Suspended Monolayer and Few-Layer MoS2 2D Crystals. ACS Nano 7:1072-1080. doi: 10.1021/nn303973r

42. Novoselov KS, Jiang D, Schedin F, et al (2005) Two-dimensional atomic crystals. Proc Natl Acad Sci U S A 102:10451-10453. doi: 10.1073/pnas.0502848102

43. Bertolazzi S, Krasnozhon D, Kis A (2013) Nonvolatile memory cells based on MoS2/graphene heterostructures. ACS Nano 7:3246-3252. doi: 10.1021/nn3059136

44. Lee G-H, Yu Y-J, Cui X, et al (2013) Flexible and Transparent MoS 2 Field-Effect Transistors on Hexagonal Boron Nitride-Graphene Heterostructures. ACS Nano 7:79317936. doi: 10.1021/nn402954e

45. He Q, Zeng Z, Yin Z, et al (2012) Fabrication of flexible MoS2 thin-film transistor arrays for practical gas-sensing applications. Small 8:2994-2999. doi: 10.1002/smll.201201224

46. Lee C, Yan H, Brus LE, et al (2010) Anomalous Lattice Vibrations of Single- and Few- 
Layer MoS2. ACS Nano 4:2695-2700. doi: 10.1021/nn1003937

47. Li H, Zhang Q, Yap CCR, et al (2012) From Bulk to Monolayer MoS2: Evolution of Raman Scattering. Adv Funct Mater 22:1385-1390. doi: 10.1002/adfm.201102111

48. Chakraborty B, Matte HSSR, Sood AK, Rao CNR (2013) Layer-dependent resonant Raman scattering of a few layer MoS2. J Raman Spectrosc 44:92-96. doi: $10.1002 /$ jrs.4147

49. Najmaei S, Ajayan PM, Lou J (2013) Quantitative analysis of the temperature dependency in Raman active vibrational modes of molybdenum disulfide atomic layers. Nanoscale 5:9758-9763. doi: 10.1039/c3nr02567e

50. Najmaei S, Liu Z, Ajayan PM, Lou J (2012) Thermal effects on the characteristic Raman spectrum of molybdenum disulfide $(\mathrm{MoS} 2)$ of varying thicknesses. Appl Phys Lett. doi: $10.1063 / 1.3673907$

51. Dieterle M, Mestl G (2002) Raman spectroscopy of molybdenum oxides. Phys Chem Chem Phys 4:822-826. doi: 10.1039/b107046k

52. Botz R, Wehner H, Schmitt M, et al (2002) Thermogenic hydrocarbons from the offshore Calypso hydrothermal field, Bay of Plenty, New Zealand. Chem Geol 186:235-248. doi: $10.1016 / \mathrm{S} 0009-2541(01) 00418-1$

53. Rogge WF, Hildemann LM, Mazurek M a., et al (1993) Sources of fine organic aerosol. 2. Noncatalyst and catalyst-equipped automobiles and heavy-duty diesel trucks. Environ Sci Technol 27:636-651. doi: 10.1021/es00041a007

54. WHO (1986) IARC Working group on the evaluation of the carcinogenic risk of chemicals to humans tobacco smoking. WHO Int agency Res cancer Vol 38 38:1-432.

55. Johnsen AR, Wick LY, Harms H (2005) Principles of microbial PAH-degradation in soil. Environ Pollut 133:71-84. doi: 10.1016/j.envpol.2004.04.015

56. Tielens AGGM (2008) Interstellar Polycyclic Aromatic Hydrocarbon Molecules *. Annu Rev Astron Astrophys 46:289-337. doi: 10.1146/annurev astro.46.060407.145211 
57. Olsbye U, Svelle S, Bjørgen M, et al (2012) Conversion of Methanol to Hydrocarbons: How Zeolite Cavity and Pore Size Controls Product Selectivity. Angew ChemieInternational Ed 51:5810-5831. doi: 10.1002/anie.201103657

58. Olsbye U, Svelle S, Lillerud KP, et al (2015) The formation and degradation of active species during methanol conversion over protonated zeotype catalysts. Chem Soc Rev. doi: $10.1039 / \mathrm{c} 5 \mathrm{cs} 00304 \mathrm{k}$

59. Kvisle S, Fuglerud T, Kolboe S, et al (2008) Methanol-to-Hydrocarbons. In: Handb. Heterog. Catal. Wiley-VCH Verlag GmbH \& Co. KGaA, Weinheim, Germany, pp 29502965

60. Ferguson J, Reeves LW, Schneider WG (1957) Vapor Absorption Spectra and Oscillator Strengths of Naphthalene, Anthracene, and Pyrene. Can J Chem 35:1117-1136. doi: $10.1139 / \mathrm{v} 57-152$

61. Ferrari a., Robertson J (2000) Interpretation of Raman spectra of disordered and amorphous carbon. Phys Rev B 61:14095-14107. doi: 10.1103/PhysRevB.61.14095

62. Ferrari AC, Robertson J (2001) Resonant Raman spectroscopy of disordered, amorphous, and diamondlike carbon. Phys Rev B 64:75414. doi: 10.1103/PhysRevB.64.075414

63. Shimanouchi T (1972) Tables of Molecular Vibrational Frequencies Consolidate Volume I. Natl Bur Stand. doi: 10.1063/1.555560 